\title{
Robotized surgical assistant in neurosurgery: Anaesthetic implications!
}

Sir,

Robots as an aid to the surgical procedures are the modern application of surgery. These robots are developed to improve the capabilities of surgeons performing both minimally invasive surgery and open surgery. Robot-assisted surgery comes at a high cost but can become cost-effective if performed by highly experienced surgeons and in mostly high-volume centres ${ }^{[1]}$ Robot-assisted surgeries have been performed in many complex procedures in patients posted for cardiac, thoracic or gynaecological procedures. ${ }^{[2-4]}$ Neurosurgery is one of the major fields where the application of robots is feasible. Robots have been incorporated into various stereotactic and endoscopic neurosurgical procedures. ${ }^{[5-7]}$ Other key neurosurgical applications for robots include robotised microscope, ${ }^{[8]}$ telepresence, ${ }^{[9]}$ and tumour resection. ${ }^{[10]}$ The first neurosurgical robot 'NeuroMate' was made commercially available in 1997. ${ }^{[11]}$ The evolution of neurosurgical robots from stereotactic systems is capable of performing both craniofacial and spine surgeries. ${ }^{[12,13]}$ Other advantages of robot-assisted surgeries include less blood loss, less transfusions, smaller incision, less pain and shorter hospital stay. ${ }^{[14]}$

Robotised surgical assistant (ROSA) device is an integrated platform solution combining software for neurosurgical planning and navigation, with a robotic arm of high technology. This device is comparable to a 'Global Positioning System (GPS)' for the brain. These robots can be divided into active and passive system. An active robotic system, robot actively interacts with a patient, allows more complicated motion to be realised. Where as in a passive robotic system, surgeon provides the physical energy to drive the surgical tool. ${ }^{[15]}$ They can be used in any type of cranial procedure that requires surgical planning with pre-operative data and precise position and handling of instruments. It uses facial recognition technology to create a GPS map of the patient's brain.

- Dedicated to minimally invasive surgeries of the central nervous system

- Increases the precision and reliability of the gestures and reduce the operating time

- ROSA allows frameless stereotactic procedures increasing accuracy and reducing operative time

- It is especially effective for stereoelectroencephalography (SEEG), ${ }^{[16]}$ deep brain stimulation, endoscopic procedures, brain tumour resection, brain biopsy and paediatric surgery

- SEEG epilepsy surgery, a minimally invasive procedure, is used to identify areas of the brain where epileptic seizures originate. We can actually find out where the seizures are coming from and stop them from occurring

- It helps burning deep-seated tumours that are otherwise difficult to access through surgery by a process called laser ablation of brain tumours.

Involvement of ROSA in surgical procedure result in the precise excision of tumour with minimal dissection leading to less scarring, minimal consumption of anaesthetics and opioids, ${ }^{[17]}$ minimal blood loss, lesser transfusions, less post-operative pain along with faster recovery ${ }^{[17]}$ and shorter stay in Intensive Care Unit. The disadvantages with ROSA include: Inability to allow change in patient position, tearing or puncturing of vessels or internal organs if patient is moved while robotic instruments are docked, extreme positioning leading to physiological changes, prolonged surgery leading to pressure injury, invasion of anaesthesia workspace, difficult access to airway, long tubing for both monitoring and anaesthesia workstation, requirement of large operating room space, injury to patient because of bulkiness of the robots and their infrastructure and high cost. Robot-assisted surgeries are contraindicated in situations pertaining to inability of patients to tolerate general anaesthesia, abnormal coagulation profile, severe obesity, and severe cardiac or pulmonary disease.

Pre-operative anaesthetic management apart from routine instructions should include proper counselling of the patient about robot-assisted surgery in view of prolonged operating time and high cost of the procedure. Intra-operative anaesthetic considerations in neurosurgery by ROSA encompasses invasive monitoring when the procedure is performed by inexperienced surgeon, arterial blood pressure monitoring in patients with cardiac or pulmonary disease, an absolute paralysis during the period when robot is fixed and applied to the patient (continuous infusion with neuromuscular monitoring has been advocated), low threshold for advanced monitoring, aborting the robotic procedure in case of uncontrollable bleeding at surgical site, and finally, the provision for emergent undocking of robot should be kept ready. One can cardiovert the irregular rhythm with the robot docked.

As discussed above there are several pitfalls with robot-assisted surgery which should be kept in mind 
while managing patients posted for neurosurgery. Evidence suggests that robot-assisted surgeries take longer time but may be associated with a shorter hospital stay. ${ }^{[18]}$ Evidence on robot-assisted surgery for neurosurgery, however, is lacking. Hence, welldesigned, large randomised controlled trials, on the use of ROSA in neurosurgery, are required to predict long-term outcome measures such as cognitive function, quality of life, patient satisfaction and cost effectiveness of the procedure.

\section{Indu Kapoor, Girija P. Rath}

Department of Neuroanaesthesiology and Critical Care, Neuroscience Centre, All India Institute of Medical Sciences, New Delhi, India

Address for correspondence: Dr. Indu Kapoor,

Department of Neuroanaesthesiology and Critical Care, Neuroscience Centre, All India Institute of Medical Sciences, New Delhi, India. E-mail: dr.indu.me@gmail.com

\section{REFERENCES}

1. Liberman D, Trinh QD, Jeldres C, Zorn KC. Is robotic surgery cost-effective: Yes. Curr Opin Urol 2012;22:61-5.

2. Ullah W,McLean A,Hunter RJ,Baker V,Richmond L,Cantor EJ, et al. Randomized trial comparing robotic to manual ablation for atrial fibrillation. Heart Rhythm 2014;11:1862-9.

3. van der Sluis PC, Ruurda JP, van der Horst S, Verhage RJ, Besselink MG, Prins MJ, et al. Robot-assisted minimally invasive thoraco-laparoscopic esophagectomy versus open transthoracic esophagectomy for resectable esophageal cancer, a randomized controlled trial (ROBOT trial). Trials 2012;13:230.

4. Corrado G, Cutillo G, Pomati G, Mancini E, Sperduti I, Patrizi L, et al. Surgical and oncological outcome of robotic surgery compared to laparoscopic and abdominal surgery in the management of endometrial cancer. Eur J Surg Oncol 2015;41:1074-81.

5. Louw DF, Fielding T, McBeth PB, Gregoris D, Newhook P, Sutherland GR. Surgical robotics: A review and neurosurgical prototype development. Neurosurgery 2004;54:525-36.

6. McBeth PB, Louw DF, Rizun PR, Sutherland GR. Robotics in neurosurgery. Am J Surg 2004;188 4A Suppl: 68S-75S.

7. Awang MS, Abdullah MZ. Robotic neurosurgery: A preliminary study using an active vision-guided robotic arm for bone drilling and endoscopic manoeuvres. Malays J Med Sci 2011;18:53-7.

8. Giorgi C, Eisenberg H, Costi G, Gallo E, Garibotto G, Casolino DS. Robot-assisted microscope for neurosurgery.
J Image Guid Surg 1995;1:158-63.

9. Hongo K, Goto T, Kakizawa Y, Koyama J, Kawai T, Kan K, et al. Micromanipulator system (NeuRobot): Clinical application in neurosurgery. Int Congr Ser 2003;1256:509-13.

10. Benabid AL, Lavallee S, Hoffmann D, Cinquin P, Demongeot J, Danel F. Potential use of robots in endoscopic neurosurgery. Acta Neurochir Suppl (Wien) 1992;54:93-7.

11. "Robot-Assisted Surgery: Neurosurgery". Available from: http:// www.Biomed.brown.edu. [Last retrieved on 2013 Jun 25].

12. Gui H, Zhang S, Luan N, Lin Y, Shen SG, Bautista JS. A novel system for navigation-and robot-assisted craniofacial surgery: Establishment of the principle prototype. J Craniofac Surg 2015;26:e746-9.

13. Roser F, Tatagiba M, Maier G. Spinal robotics: Current applications and future perspectives. Neurosurgery 2013;72 Suppl 1:12-8.

14. Estey EP. Robotic prostatectomy: The new standard of care or a marketing success? Can Urol Assoc J 2009;3:488-90.

15. Mckay-Davies I, Bann S, Darzi A. Robotics in surgery. Stud $\mathrm{Br}$ Med J 2002;10:215-58.

16. González-MartínezJ,Bulacio J,Thompson S, Gale J,Smithason S, Najm I, et al. Technique, results, and complications related to robot-assisted stereoelectroencephalography. Neurosurgery 2016;78:169-80.

17. Cohn DE, Castellon-Larios K, Huffman L, Salani R, Fowler JM, Copeland LJ, et al. A prospective, comparative study for the evaluation of postoperative pain and quality of recovery in patients undergoing robotic versus open hysterectomy for staging of endometrial cancer. J Minim Invasive Gynecol 2016. pii: S1553-465000033-9.

18. Liu H, Lawrie TA, Lu D, Song H,Wang L, Shi G. Robot-assisted surgery in gynaecology. Cochrane Database Syst Rev 2014;12:CD011422.

This is an open access article distributed under the terms of the Creative Commons Attribution-NonCommercial-ShareAlike 3.0 License, which allows others to remix, tweak, and build upon the work non-commercially, as long as the author is credited and the new creations are licensed under the identical terms.

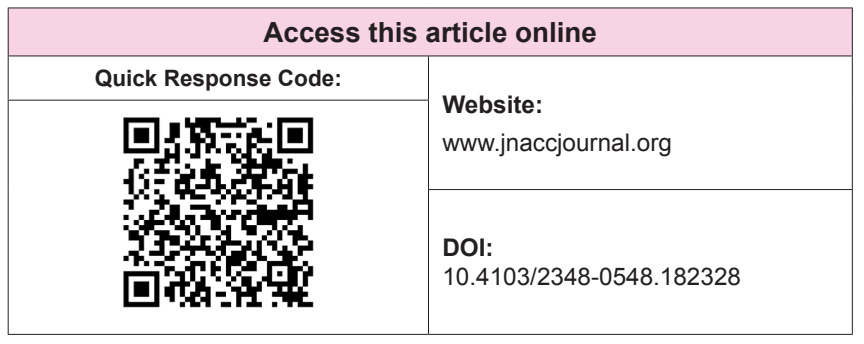

How to cite this article: Kapoor I, Rath GP. Robotized surgical assistant in neurosurgery: Anaesthetic implications!. J Neuroanaesthesiol Crit Care 2016;3:151-2. 